\title{
The allocation of jurisdiction in international antitrust
}

\author{
By Damien J. Neven (University of Lausanne) \\ and \\ Lars-Hendrik Röller (WZB, Humbold University and INSEAD)
}

September 1999

Paper prepared for presentation at the EEA meeting at Santiago de Compostela. We would like to thank Henrik Horn, Petros Mavroidis and participants at the NBER/CEPR workshop on the new trade agenda for insightful comments on a previous version of this paper. 


\begin{abstract}
In this paper, we consider the organisation of international antitrust as an issue of institution design which involves a trade-off between an inadequate internalisation of external effects across jurisdictions and the risk of capture in a centralised agency. We focus on the first element of the trade-off and on merger control. We first point out that the current framework of public international law allows for wide discretion in the assertion of jurisdiction. We then consider various allocation of jurisdictions in a stylised model of international merger control which attempts to capture the essential features of the objectives being pursued and of the procedures being implemented in the major jurisdictions. We find that in this framework, much of the scope for conflict disappears. The fact that conflicts actually often arise in global industries must then be associated with the pursuit of objectives that antitrust authorities are not supposed to pursue. We also find that the allocation of jurisdiction matters surprisingly little for the final outcome.
\end{abstract}




\section{Introduction}

A number of high profile cases have recently underlined potential conflicts between countries in the implementation of antitrust rules. For instance, the EU commission decided in 1991 to ban the acquisition of de Havilland, a Canadian company active in the regional aircraft market by a French/Italian consortium (Aérospatiale/Alenia). The Canadian antitrust authorities however had allowed the deal to go through and both the French and Italian government had expressed support. This is thus an instance where two authorities reviewed the same operation and where the most restrictive authority prevailed. More recently, in 1997, the merger between Mc Donnell-Douglas and Boeing led to an important conflict between US and EU antitrust authorities, which spilled over to their political masters. This merger was allowed by US authorities at a time when EU authorities were expressing serious concerns. The conflict escalated and a trade war was avoided at the last minute when the parties accepted to modify their operation to satisfy the demands of the EU. Another serious conflict has arisen this spring when the European Court of Justice confirmed a decision by the European Commission to ban the merger between Lonrho and Gencor, two South African companies involved in the mining and processing of platinum. The South African antitrust authority has however allowed the operation to go through. Its Minister of trade and industry has even officially provided support to the private parties in front of the European Commission.

If the active enforcement of antitrust rules has been contentious, the lack of enforcement has also been a source of concern. For instance, in the recent Kodak/Fuji case, it has been alleged (by US authorities on behalf of Kodak) that the Japanese antitrust authority (the Fair Trade Commission) had failed to implement its own legislation towards vertical restraints in the distribution of photographic film in Japan. As such failure to implement domestic laws would have the effect of erecting an import barrier, it has been the object of an arbitration in the WTO.

These cases illustrate the existence of conflict in the implementation of competition 
policy among different jurisdictions and raise the issue of how such implementation should be organised. This question which had been much debated when merger control was (partially) centralised in the EU has again become the focus of attention among policy makers, partially in recognition of the fact that current attempts to reduce conflicts will not suffice ${ }^{1}$.

Most of the policy discussion has however focused on legal and institutional aspects. From an economic point of view, the organisation of international antitrust has been discussed (see for instance, Bacchetta et al., (1997) or Neven et al., (1994)) as an issue of institutional design, with a trade-off between centralised decision making at the level of a supra-national organisation, and delegated decision making to lower levels of government at the level of independent states. The terms of such trade-off have been widely discussed in public economics and applied to the area of antitrust (see for instance, Neven et al., (1994)).

The benefits of centralisation usually consist primarily in the internalisation of economic spillovers across national boundaries. Indeed, independent regulators have an incentive to take into account the effects of anti-competitive practice only in so far as they take place within their own jurisdiction. Hence, if the geographical scope of the effects of an anticompetitive practice is not included in a particular jurisdiction, external effects will not be taken into account. A central agency, by contrast, will ensure that all the effects of a particular policy decision are taken into account and are not given differential consideration according to the country on whose citizens they happen to fall.

However, centralisation also has costs, notably the risk of making regulatory policymakers more remote from the economies whose firms and consumers they influence by their actions. Accountability is another concern at the level of centralised agencies: regulators who are unaccountable do not necessarily pursue the objectives they have been assigned, but may simply use their discretion to favour particular interests (for reasons that may be innocent or sinister). This lack of accountability may in turn be due to one or more of several factors. First, citizens and voters may have less information about the operation of

\footnotetext{
${ }^{1}$ Antitrust authorities have responded to the situation by entering into or upgrading bi-lateral co-operation agreements which are meant to reduce the scope for conflict by sharing information and providing incentive for building consensus (see for instance Montini (1998)). Karel Van Miert, the former competition commissioner has openly admitted that such arrangements are insufficient to handle situations like the Boeing/Mc DonnellDouglas merger (EU Competition newsletter, 1998). There is also widespread recognition that current WTO rules are inadequate to handle the matter. See for instance Bacchetta et al. 1997 or Fox, 1997.
} 
centralised institutions than about those of their own country or region, so there may be less political pressure to ensure that these institutions function well. Secondly, even with adequate information, citizens and voters may have difficulty holding such institutions to account because this relies on concerted action among all those affected, which is much harder to achieve at a centralized level than for local or regional groups. Admittedly, intermediate levels of governments could sometimes substitute for voters and citizens and enhance the accountability of centralised agencies. For instance, the scrutiny of the EU Commission decisions by Members states is, at least in some areas, an important constraint on its decisions. Thirdly, holding centralized institutions to account is often difficult because it is hard to see how alternative policies would function; one of the advantages of decentralization is that "competition among regulators" provides some benchmark; it helps to reveal by comparison the strengths and shortcomings of any particular system or set of policies ${ }^{2}$. Hence, the political economy of central agencies differs in some important ways from that found at lower levels of government. The presumption that centralised agencies might be more prone to capture is actually at the core of the principle of subsidiarity.

Overall, then, centralisation is most appropriate when externalities across countries are large relative to the risks of enhanced "capture" of centralised institutions. A discussion of international antitrust should thus consider both. Neither have been given much attention in the debate so far. This paper will consider the first aspect, namely the extent to which decentralised decision making will lead to inefficient decisions, because of external effects. We first review the existing literature on the matter.

\section{External effects across jurisdictions - existing literature}

Head and Ries (1997) propose a model where jurisdiction is dependent on the location of firms headquarters. They consider international mergers with regulators which maximise welfare (consumers surplus and the share of profits accruing to domestic citizens) and take discrete decisions. They focus on type II errors (situation where a merger is not banned even though it would be by a central agency), which seems a priori surprising given that type II errors are likely to be the least concern in the presence of multiple jurisdictions. They

\footnotetext{
${ }^{2}$ That is not to say, however, that competition between jurisdictions is always desirable - as it may exacerbate external effects (see below).
} 
confirm (proposition 1, p 1109) that if all countries affected by a merger have jurisdictions, no merger which reduces global welfare will be allowed (type II errors will be nil). They also show, considering mergers which increase price, that type II errors will arise when no country with jurisdiction represents a sufficient proportion of consumers so that it will want to block the merger. The intuition behind this result becomes straightforward if one considers an extreme case : consider two countries which each hosts one headquarter but no consumers - which are all concentrated in a third country. Clearly, the merger will not be blocked even though it should be (at least if it does not involve efficiency benefits - so that the merger is akin to a reduction in the number of firm - à la Salant et al). More generally, it is clear that if firms are not located where the consumers are, type II errors may be large (under the allocation of jurisdiction assumed here). Notice however that this result is highly dependent on the objective function of the regulator (if he is not concerned about profit, all it takes is for one consumer to be located within a jurisdiction to reduce type II errors to zero).

Rather than assuming that regulators maximise welfare, Barros and Cabral (1994) adopt the framework of Farell and Shapiro (1990) and accordingly focus on the external effect of a merger (the effect on consumers and competitors). They are mostly concerned with a possible merger between domestic firms and wonder whether a decision by a national authority would be different from that of a global authority. They confirm the presumption discussed above namely that if a domestic economy is a reduced scale version of the broader area (specifically if the share of demand from the domestic economy is equal to its share of supply), decisions by domestic and global regulators will coincide. However, if the share of domestic demand exceeds the share of domestic supply, a domestic regulator will ban mergers that a global regulators would allow (type I errors will emerge). The reason is of course that consumers (in their model) are always hurt by the mergers whereas the competitors of the merging firms benefit. Facing a more than proportional representation of consumers, it is not a surprise that domestic regulators will be excessively strict. Of course, the reverse will be true as well : if the share of domestic supply exceeds the share of domestic demand in the broader area, a domestic regulator will allow mergers that a global regulators would ban (type II errors emerge). 
To summarise, the existing literature ${ }^{3}$ suggests that the existence of a distortion will depend on the distribution of gainers and losers within countries having jurisdiction relative to that prevailing in the broader area. This literature does not focus on the evaluation of different rules for the allocation of jurisdiction beyond the alternative of a global regulator versus one possible allocation of jurisdiction depending on the location of firm headquarters. The example of international conflicts discussed above however suggest that it may be useful to consider more complex allocations of jurisdictions. The outcome of decentralised decision making will indeed depend on the interaction between the independent regulators. That is, independent antitrust authorities will also compete through their decision. The strategic interactions between them will affect the final outcome but these interactions can also be constrained by particular "rules of competition".

In the existing literature, it is also assumed that the regulator maximise welfare or considers external effects. It would seem however that regulators interact with various constituencies in taking their decisions and it may be useful to model these interactions explicitly.

\section{The international allocation of jurisdiction}

In the case of international antitrust, the main "rule" affecting competition between independent authorities is the rule governing the assertion of jurisdiction (see Neven and Mavroidis, 1999 for a discussion of the issue). Both the EU and the US now rely on the so called "effects doctrine" such that a country asserts jurisdiction when it is affected by a particular practice ; for instance, the EU has asserted jurisdiction on US producers gathered in an export cartel in the Wood pulp case because the effects of the cartels were felt in the Community. Recently, both the US and the EU have effectively extended the effects doctrine to include situation where effects are only felt by domestic producers and not by consumers. In 1992, the United States promulgated a "Restatement" of Guidelines on International Antitrust enforcement, in which a footnote (footnote 159) was deleted. ${ }^{4}$ Up to this point in

\footnotetext{
${ }^{3}$ A number of papers have also formalised the implementation of competition policy and the competition between antitrust agencies in more specific contexts. Richardson (1997) and Horn and Levinsohn (1998) consider a two country framework and analyse how trade liberalisation will affect countries' incentives in implementing a competition policy through which they fix the number of firms.

${ }^{4}$ See Fox (1997) on this issue.
} 
time, the application of the US antitrust law was only applied when the interests of US consumers were at stake. It is now clear that these laws will also be applied when the interests of US firms are affected.

The decision by the EC Commission on the Boeing/Mc Donnell-Douglass merger is also revealing. In this case, the EU asserted jurisdiction, invoking as grounds, inter alia, the damage that such a merger would cause to the major EC producer (and competitor of the two merging firms) Airbus. One can also argue that the remedies imposed by the EU commission were only meant to protect the profits of Airbus. Indeed, the exclusive agreements that Boeing had concluded with US airlines, which had to be cancelled for the deal be allowed, would not affect the European Consumers but only the profits of Airbus.

Hence, it appears that in the current legal framework, independent jurisdiction can easily assert their authority. It will thus be particularly interesting to compare the outcomes arising from such a simultaneous assertion of jurisdiction to alternatives and in particular the allocation of sole jurisdiction to a central authority. In principle, it is unclear, how the different rules for the allocation of jurisdictions will affect the outcome. For instance, is it that the simultaneous assertion of jurisdiction will enhance or reduce the probability of a distortion in the presence of external effects ? (relative to the decision that would be taken by a single regulator having global jurisdiction - and assuming for the time being that all regulators have the same objective function). One would expect that the simultaneous assertion of jurisdictions would reduce type II errors, i.e. the possibility that a practice is allowed by all individual jurisdictions when it would not have been allowed by the global regulator, but increase type I errors, i.e. the possibility that a practice is banned by at least one individual jurisdiction when it would have been allowed by the global regulator.

In the following section, we build a stylised model of merger control and investigate how different rules to allocate jurisdictions will affect the outcome.

\section{A stylised model of international merger control}

In this section, we investigate how different allocations of jurisdictions affect the 
outcome in a model of international merger control with external effects. The objective of this analysis is to evaluate the importance of the distortions that would arise in various alternative scenarios about the allocation of jurisdictions.

As mentioned above, the assumption that regulators simply maximise welfare (or consider external effects) is not satisfactory. It is however beyond the scope of this paper to build a model which represents the interactions between regulators and their constituencies 5 . In what follows, we thus build a stylised model of merger control which try to represent some essential features of the approach which is adopted by the main antitrust authorities.

In particular, we will assume that the authorities first define the relevant market and subsequently undertake an analysis of dominance. Such an approach is by now fairly standard in many jurisdictions and in particular in the main jurisdictions like the EU and the US. We will also assume that antitrust agencies simply carry out the task that they have been assigned. Since the implementation of the Merger guidelines in the EU, there has been a remarkable convergence between the EU and the US in the formal objective that is assigned to antitrust agencies towards mergers. The formal standard is such that a merger should not be allowed if it hurts consumers (and accordingly efficiency benefits should only be considered if they are so large that, because of cost reductions, the price to consumers will not increase). Such an approach is clearly articulated in the US merger guidelines and in article 2 (b) of the merger regulation. Accordingly, we will assume that antitrust authorities are only concerned about consumers and, rather mechanically, evaluate mergers relative to a concentration threshold.

Consider a world with two countries, $\mathrm{i}=1,2$ and a homogenous commodity. There is a collection of firms which can produce and sell in both countries. We can leave the competitive interactions between firms unspecified but simply assume that there is a pair of equilibrium price - one for each country - before the merger takes place.

Assume that there is merger task force in each country which evaluates mergers by first delineating the relevant market and subsequently deciding to allow or ban the merger on the basis of the market share of the merging parties in the relevant market. Specifically, 
assume the relevant is market is determined according the SSNIP test - i.e. by asking whether a hypothetical monopolist could increase price profitably by $\mathrm{x} \%$ above the competitive level.

The extent to which a hypothetical monopolist who maximises profit would increase price by $\mathrm{x} \%$ is inversely proportional to the elasticity of demand that it would face. We assimilate the profitable increase in price of the SSNIP test with the profit maximising increase in price. Hence, we assume that the relevant market can be determined by the elasticity of demand. If the elasticity of demand (evaluated at the competitive price- say $\varepsilon_{\mathrm{i}}$ ) is below some benchmark (say K), market $\mathrm{i}$ will be considered to be relevant for the sake of antitrust analysis.

We assume that the elasticity in market 1 is lower than that of market 2 , i. e. $\varepsilon_{1} \leq \varepsilon_{2}$, and that the difference in elasticity is associated with a difference in size (so that market 1 is larger). A demand model where these conditions are explicitly derived can be found in Neven and Röller (1999).

It is important to note that in this framework different antitrust authorities could take different views on the relevant market. In particular, when $\varepsilon_{1}<K<\varepsilon_{2}$, the antitrust authority in the large market will decide that its own jurisdiction is a relevant market, whereas the antitrust authority in market 2 will decide that its own jurisdiction is too small (a hypothetical monopolist would not be able to profitably raise price) and hence will consider the combination of the two markets as the relevant market for the analysis of dominance.

With respect to the analysis of dominance, we assume the simplest possible rule namely that if the market share of the merging parties is higher than $\mathrm{B}$, the merger is banned. Otherwise, it is allowed.

Consider a merger between two firms which have a market share $\mathrm{MS}_{\mathrm{i}}$ in country $\mathrm{i}$ and $\mathrm{MS}_{\mathrm{t}}$ in the overall market. In principle, there are four possible allocations of jurisdiction: either country could have sole jurisdiction, both countries could exercise jurisdictions

\footnotetext{
${ }^{5}$ This is the subject of a companion paper (Neven and Röller, (1999))
} 
simultaneously and finally a supra-national authority can have jurisdiction. As indicated above, individual countries can easily assert jurisdiction. Accordingly, we focus on the comparison between the simultaneous assertion of jurisdiction and the exercise of authority by a centralised agency.

We assume that when a merger is banned by a particular jurisdiction, it cannot take place in a reduced form in another jurisdiction. That is, we neglect the possibility of having partial deals or remedies for particular jurisdictions. This assumption tends to reinforce the importance of external effects across jurisdictions and the prospect for conflicts.

There are three distinct parameter ranges to consider for the distribution of market shares (i.e. $\mathrm{MS}_{\mathrm{i}}<\mathrm{B}, \mathrm{i}=1,2 ; \mathrm{MS}_{\mathrm{i}}>\mathrm{B}, \mathrm{i}=1,2 ; \mathrm{MS}_{\mathrm{i}}<\mathrm{B}<\mathrm{MS}_{\mathrm{j}}$ ) and for the elasticities which delineate the relevant market $\left(\varepsilon_{1}>\mathrm{K}, \varepsilon_{1}<\varepsilon_{2}<\mathrm{K}\right.$ and $\left.\varepsilon_{1}<\mathrm{K}<\varepsilon_{2}\right)$. Hence there are nine distinct ranges of parameter.

Remark 1: If $\mathrm{MS}_{\mathrm{i}}<\mathrm{B}, \mathrm{i}=1,2$, or $\mathrm{MS}_{\mathrm{i}}>\mathrm{B}, \mathrm{i}=1,2$, then the allocation of jurisdiction does not matter. Furthermore, there is no conflict.

The reason is straightforward. If the market share of the merging firms exceeds (falls short) of the threshold in both market, then it will also exceed (fall short of) the threshold for the overall market ( $\mathrm{MS}_{\mathrm{t}}$ will be on the same side of the threshold as in the individual markets). Hence, whatever the market definition adopted by the authority in charge, the decision will be the same. For six cases (out of 9), the allocation does not matter. There are three cases left to consider.

Remark 2 : If $\varepsilon_{1}>\mathrm{K}$, (and $\mathrm{MS}_{\mathrm{i}}<\mathrm{B}<\mathrm{MS}_{\mathrm{j}}$ ) then the allocation of jurisdiction does not matter. Furthermore, there is no conflict.

The reason is as follows. Whenever $\varepsilon_{1}>\mathrm{K}$, then a competition authority in market 1 (the large market) will conclude that the relevant market is the combination of both markets. 
Given that $\varepsilon_{1} \leq \varepsilon_{2}$, the competition authority in the small country will reach the same conclusion. As a consequence, both authorities, as well as a supra-national authority will consider $\mathrm{MS}_{\mathrm{t}}$ in the analysis of dominance.

When the relevant market is broad, the jurisdiction can actually be allocated to any country which belongs to the relevant market. The intuition behind this observation is that any subset of a relevant market is, from a competition point of view, a reduced scale version of the broader market.

Hence, it appears that contrary to received wisdom, "global" industries are not those where the conflict between jurisdiction should arise! The fact that conflicts actually often arise in such industries must then be associated with the pursuit of objectives that antitrust authorities are not supposed to pursue (in the model as well as according to their statutes at least for the US and the EU). Conflict across jurisdictions may be essentially a matter arising from the political economy of implementation and not from external effects.

There are thus two cases left to consider. First, the case where $\varepsilon_{1}<\varepsilon_{2}<\mathrm{K}$ (and $\mathrm{MS}_{\mathrm{i}}$ $<\mathrm{B}<\mathrm{MS}_{\mathrm{j}}$ ) such that both antitrust authorities would conclude that their own jurisdiction is a relevant market and the case where $\varepsilon_{1}<\mathrm{K}<\varepsilon_{2} \quad$ (and $\mathrm{MS}_{\mathrm{i}}<\mathrm{B}<\mathrm{MS}_{\mathrm{j}}$ ) such that there will be a conflict over market definition.

Remark 3: If $\varepsilon_{1}<\varepsilon_{2}<\mathrm{K}$, and $\mathrm{MS}_{\mathrm{i}}<\mathrm{B}<\mathrm{MS}_{\mathrm{j}}$, the allocation of jurisdiction does not matter. Furthermore, there is always conflict.

In this case, both national authorities (as well as a centralised agency) would recognise that each country is a separate relevant market and take a decision on the basis of dominance in its own market. One authority will always ban the merger (leading to a conflict across countries). Under a simultaneous assertion of jurisdiction, the merger will thus be banned. This outcome will also emerge if jurisdiction is given to a centralised authority (which by assumption could not take separate decisions across relevant markets). 
We now consider the last case $\left(\varepsilon_{1}<\mathrm{K}<\varepsilon_{2}\right.$ and $\left.\mathrm{MS}_{\mathrm{i}}<\mathrm{B}<\mathrm{MS}_{\mathrm{j}}\right)$ where there is a conflict over the definition of the relevant market such that the authority in market 1 considers its own market as relevant, whereas the authority in market 2 considers the combination of the two markets as relevant. In this case, the existence of conflict will depend on the actual distribution of market shares in the two countries. The type and likelihood of conflict that may arise and its consequences for institution design are further analysed in Neven and Röller (1999). Regarding the allocation of jurisdiction, the following conclusion can be drawn.

Remark 4: If $\varepsilon_{1}<\mathrm{K}<\varepsilon_{2}$ and $\mathrm{MS}_{\mathrm{i}}<\mathrm{B}<\mathrm{MS}_{\mathrm{j}}$, the allocation of jurisdiction does not matter if the centralised agency initiates the process of market definition from the large country. If the process of market definition starts from the smaller country, the allocation of jurisdiction may matter.

Whenever a centralised agency initiates market definition from the large country, it will evaluate dominance both in the large country and in the broader area. Hence, the outcome will coincide with the simultaneous assertion of jurisdiction. Furthermore, as shown in Neven and Röller (1999), conflict between national authorities will arise depending on the distribution of market shares. Of course, in the absence of conflict, the allocation of jurisdiction will not matter. In the presence of conflict, if the central agency initiates market definition from the small country, it will take the same decision as country 2. Then, there is some parameter range for which the merger would be allowed (by the centralised agency and country 2 - but not by country 1 ) and hence where the outcome under a centralised decision making will differ from that arising under a simultaneous assertion of jurisdiction. This precise conditions under which jurisdiction matters are derived in Neven and Röller (1999).

\section{Conclusion}

In this paper, we consider the organisation of international antitrust as an issue of institutional design which involves a trade-off between an inadequate internalisation of 
external effects across jurisdictions and the risk of capture in a centralised agency. We focus on the first element of the trade-off and on merger control.

The existing literature has considered potential distortions arising from decentralised implementation of merger control and has highlighted the role of the distribution of gainers and losers within the countries having jurisdiction relative to that prevailing in the broader area. Against this background, we first observe that the current framework of public international law allows for wide discretion in the assertion of jurisdiction. We then consider a stylised model of international merger control which attempts to capture the essential features of the objectives being pursued and of the procedures being implemented in the major jurisdictions.

We observe that in our framework, the allocation of jurisdiction matters surprisingly little for the final outcome. In particular, the simultaneous assertion of jurisdiction and a decision by a central agency will almost always lead to the same outcome. We also find the scope for conflict maybe smaller than what has been highlighted in the literature so far. We observe that when there is no issue about the allocation of profits, much of the scope for conflict disappears. In particular, when the relevant market encompasses all jurisdictions concerned, as would be the case in "global" industries, conflict will only arise if antitrust agencies pursue objectives that they are not supposed to pursue. 


\section{Bibliography}

Bacchetta, M., H. Horn and P: Mavroidis, (1997), Do negative spillovers from nationally pursued competition policies provide a case for multilateral competition rules, mimeo, WTO, Geneva.

Barros, P. and L. Cabral, (1994), Merger policy in open economies, European Economic Review, 38, 1041-1055

Farell, J. and C. Shapiro, (1990), Horizontal mergers: An equilibrium analysis, American Economic Review, March, 107-126

Fox, E., (1998), International antitrust : against minimum rules; for cosmopolitan principles, The Antitrust Bulletin, Spring, 5-13

Head, K. and J. Ries, (1997), International mergers and welfare under decentralised competition policy, Canadian Journal of Economics, XXX, 4b, 1104- 1123

Horn, H. and J. Levinsohn, (1998), Merger policies and trade liberalisation, mimeo, WTO, Geneva

Mavroidis, P. and D. Neven, (1999), Some reflections on extraterritoriality in international economic law. A law and economic analyis, Mélanges offerts à Michel Waelbroeck, Vol 1 International Law, Presse Universitaire de Bruxelles, Brussels

Montini, M., (1998), Globalisation and international antitrust cooperation, mimeo, University of Sienna.

Neven, D., R. Nuttal and P. Seabright, (1994), Merger in daylight. The economics and politics of merger control in the EC, CEPR, London. 
Neven, D. and L.-H. Röller, (1999), On the design of international antitrust, DEEP Working Paper, forthcoming

Richardson, M., (1996), Trade and competition policies : concordia discors ?, mimeo, University of Otago, New Zealand 